\title{
INTERLOCKING INTRAMEDULLARY NAILING IN COMMINUTED FEMORAL SHAFT FRACTURES.
}

\author{
Abul Kalam Mohammad, Ram Kewal Shah, Awais Syed, Pradeep Gupta
}

\begin{abstract}
:
A prospective study of 20 comminuted femoral fractures, open and close, treated with interlocked intramedullary nailing. The mechanical strength of the nail and less invasive procedure has made the procedure preferable. Short Operative time and less blood loss was seen during surgical procedure. Out of 20 cases, 10 cases were taken from Nepal Medical College, Kathmandu and 10 cases from Nobel Medical College, Biratnagar, during years 2009 to 2011, which had been completed at least six months follow up. Almost all cases were relatively free from long term complication. The results were promising. All fractures healed within 6 months.
\end{abstract}

Key words: Comminuted femoral shaft Fractures, Interlocked Nail.

\section{Introduction:}

Fractures of shaft of femur are quite common .The goal of treatment is early return of extremity function usually achieved by reliable fixation of fractures.

Shortening of the limb and malalignment, along with contractures of the knee due to prolonged immobilization, have traditionally plagued the orthopedist's management of patients who have these injuries. ${ }^{\mathbf{1 , 2}}$.

Treatment goals are reliable anatomic fixation permitting rapid progress out of supine position, early return of extremity function and subsequent restitution of hip and knee motion and strength.

\section{Materials and Methods:}

In this prospective study, a total of 20 patients between 20-60 yrs old were treated for comminuted femoral fractures with interlocked intramedullary nailing system. Grade III and IV comminuted ${ }^{3}$ fractures and open femoral shaft fractures type I ${ }^{4}$ were included. Among these cases, 5 cases were taken from Jan 2009 to June 2009 at Nepal medical college, Kathmandu and 15 cases were from Nobel medical college, Biratnagar from April 2010 to Oct 2011. However comminuted femoral shaft fractures of type I and II, open femoral shaft fractures Type II \& III and segmental femoral shaft fractures were excluded. This study only aim to study purely about interlocked nailing system in fracture cases found during study period but not to compare between hospitals results. Surgical Technique: All were operated under image intensifier. The patients were put in supine position with the affected side up. A small incision over the greater trochanter area was made and the tip of greater trochanter was exposed and entry point made by using the femoral awl. Using the guide wire and the femur was reamed. The nail of appropriate size was driven slowly. The proximal 
interlocking screws were placed through the jig provided with the instrumentation. Distal interlocking screws were placed usually with free hand technique. The final position

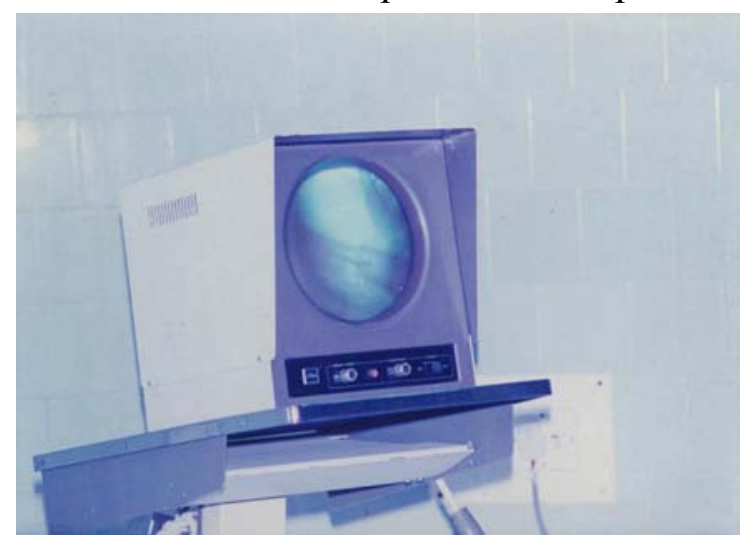

Position of guide pin being seen in image intensifier

After treatment:

All cases were encouraged to start non weight bearing crutch mobilization after 24 hours of surgery. Gentle range of motion exercises of the knee and hip joints were started on bed. Quadriceps exercises were soon encouraged ${ }^{5}$. Serial X-rays were taken at monthly intervals and gradual weight bearing was started around six weeks after surgery. All cases were followed up for at least six months to be included in the study.

\section{Results:}

We had 20 cases of interlocked intramedullary nailing. We have reported the follow-up study up to six months. There were 17 males and 3 female patients with male to female ratio 5.8:1.there were 12 patients in age group 20-29,4 in 30-39, 2 each in age group 40-49 and 50-59.Mean age was 30.6 years in male and 32.5 years in female. (Table 1). was checked under the image intensifier. The patients were given intravenous antibiotics.

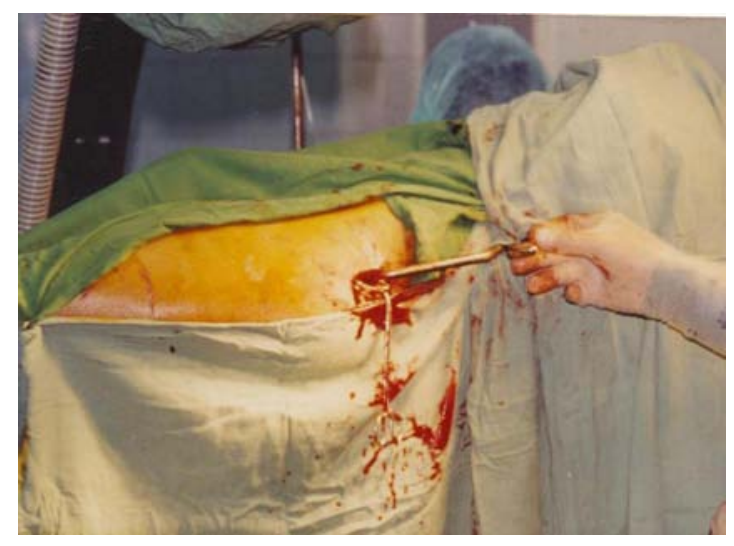

Awl being used to make starter hole in the piriformis fossa

In $75 \%$ of cases the fracture was sustained in road traffic accidents especially motorcycle accidents (50\%).In $25 \%$ of cases firearm was the cause. (Table:2)

There were 8 open fractures, 5 due to firearm and 3 due to road traffic accidents. The rest 12 fractures were close. (Table-3). There was equal number of patients in each Grade III and IV comminution. (Table: 4)

In 6 patients, there were other concomitant injuries and associated medical illness of hypertension or diabetes mellitus was found in 5 patients .These were fairly controlled before surgery was carried out.(table:5).

Most of the fractures took about 18 weeks to heal $(60 \%)$ while some $5 \%-10 \%$ healed little earlier (table 6 ) There were a total of $3(15 \%)$ postoperative complications one of each like a knee flexion $<100^{\circ}$, external rotation of femur $20^{\circ}$ and shortening of the femur $2 \mathrm{~cm}$. (Table 7) 
Table 1: Age and sex distribution $(\mathrm{n}=\mathbf{2 0})$

\begin{tabular}{llc}
\hline Age group & Male & Female \\
\hline $20-29$ & 12 & - \\
$30-39$ & 2 & 2 \\
$40-49$ & 1 & 1 \\
$50-59$ & 2 & - \\
\hline Total & 17 & 3 \\
\hline
\end{tabular}

Table 2: Mechanism of injury $(n=20)$

\begin{tabular}{lcc}
\hline Mechanism & No. of patients & \multicolumn{2}{c}{ Percentage } \\
\hline RTA & 15 & 75 \\
Fire arm & 5 & 25 \\
\hline
\end{tabular}

Table 3: Open V/s close fractures $(n=20)$

\begin{tabular}{ccc}
\hline Open v/s Close & Number & Percentage \\
\hline Close & 12 & 60 \\
open & 8 & 40 \\
\hline
\end{tabular}

Table 4: Extent of comminution (W and $H$ )

\begin{tabular}{lcc}
\hline Grade & No. of patients' & Percentage \\
\hline III & 10 & 50 \\
IV & 10 & 50 \\
\hline
\end{tabular}

Table 5: concomitant injuries $(6 / 20,30 \%)$

\begin{tabular}{|c|c|c|}
\hline Injury & Number & Percentage \\
\hline Upper limb & 1 & 5 \\
\hline Ipsilateral lower limb & 2 & 10 \\
\hline Contralateral lower limb & 1 & 5 \\
\hline Head injury & 1 & 5 \\
\hline Chest injury & 1 & 5 \\
\hline Total & 6 & 30 \\
\hline
\end{tabular}


Table 6: Fractures healing time $(n=20)$

\begin{tabular}{lcc}
\hline Time in weeks & No. of fractures healed & Percentage \\
\hline 12 & 1 & 5 \\
14 & 2 & 10 \\
16 & 2 & 10 \\
18 & 12 & 60 \\
20 & 1 & 5 \\
22 & 1 & 5 \\
24 & 1 & 5 \\
\hline Total & 20 & \multicolumn{2}{c}{100} \\
\hline
\end{tabular}

Table 7: Post of complications $(n=20)$

\begin{tabular}{lccc}
\hline Complications & No. of complications & No. of patients & Percentage \\
\hline Knee Flexion $<100^{\circ}$ & 1 & 1 & 5 \\
External rotation of femur $20^{\circ}$ & 1 & 1 & 5 \\
Shortening of the femur $2 \mathrm{~cm}$ & 1 & 1 & 5 \\
\hline Total & 3 & 3 & 15 \\
\hline
\end{tabular}

\section{Discussion:}

Interlocked intramedullary nailing system showing excellent result in both close \& open fractures. A shorter operative time, less blood loss, easy operative technique, early mobilization, shorter hospital stay and lesser post operative problems. Where ever facilities for

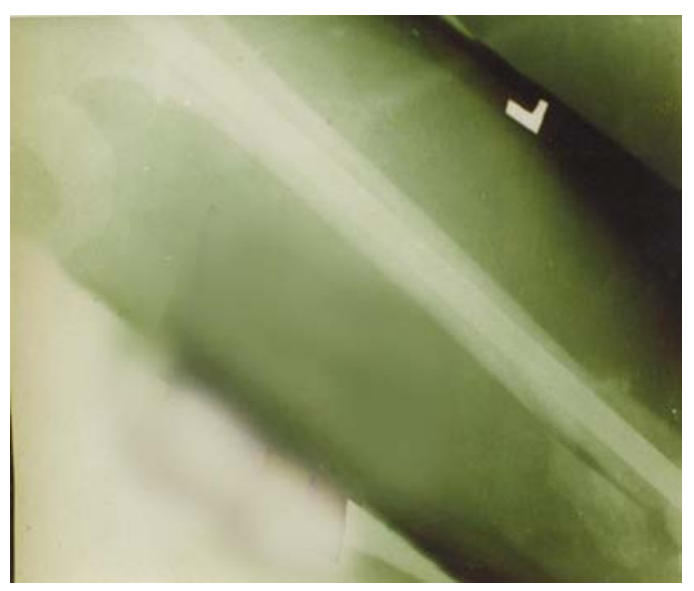

interlocked nailing became available, most orthopedic surgeons started treating fractures shaft of femur by interlocked nailing because these system control shortening, angulation \& rotation in complex fractures via locking screw. ${ }^{\mathbf{6 , 7}, \mathbf{8}}$

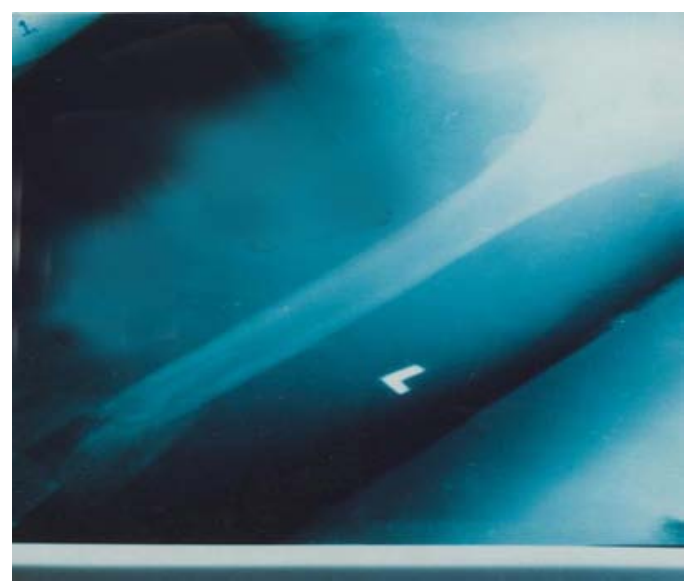


$\mathrm{X}$ - ray showing pre operative antro posterior view

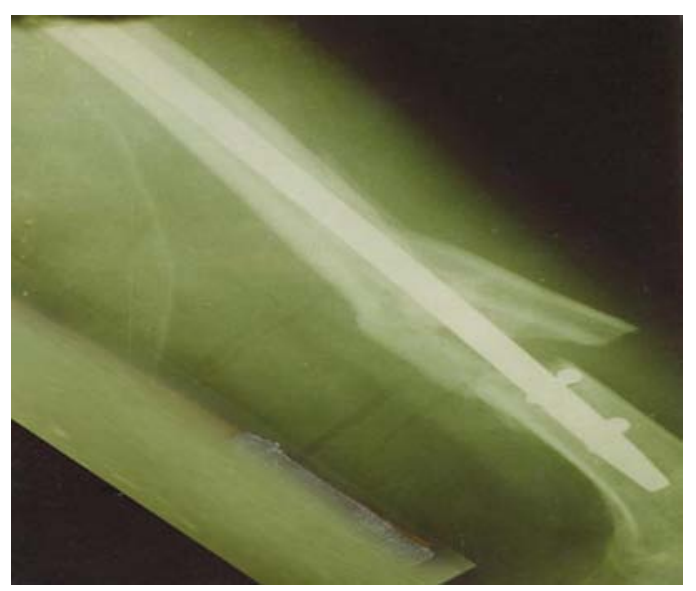

X-ray showing postoperative antero posterior view

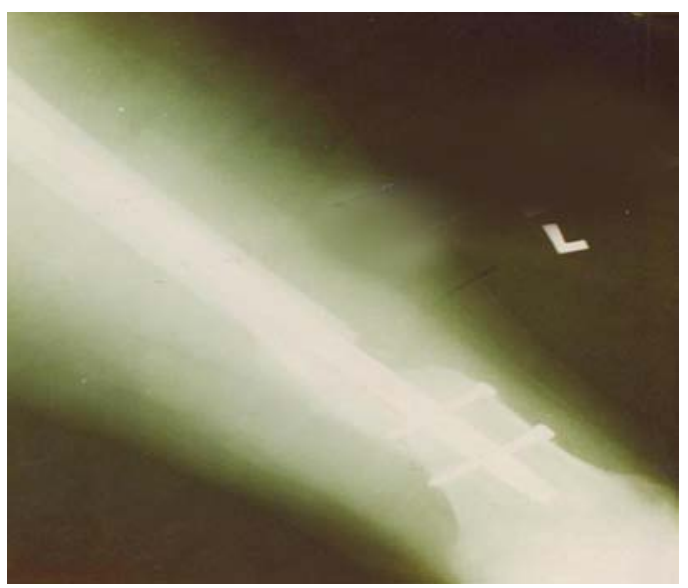

X-ray showing 12 weeks post operative antero posterior view

A deep infection after surgery on the femur is a serious complication. In our study we had no deep infection. In their study the fracture healing time is 17.7 weeks while it
X-ray showing immediate post operative lateral view

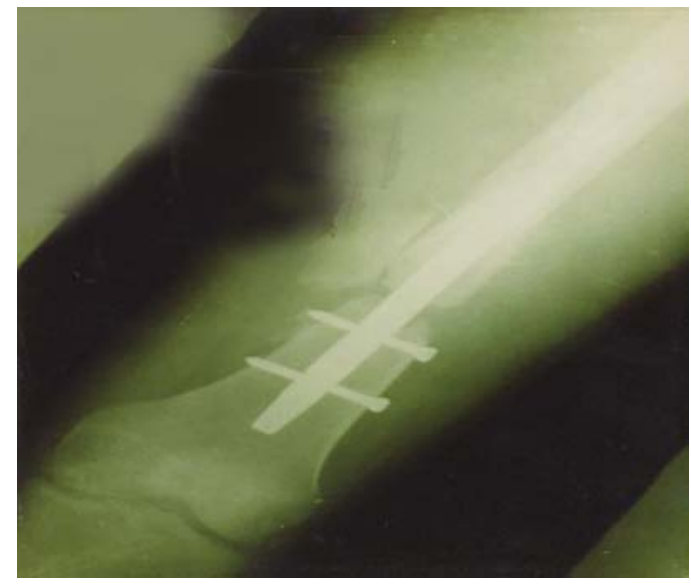

X-ray showing 12 weeks post operative lateral view

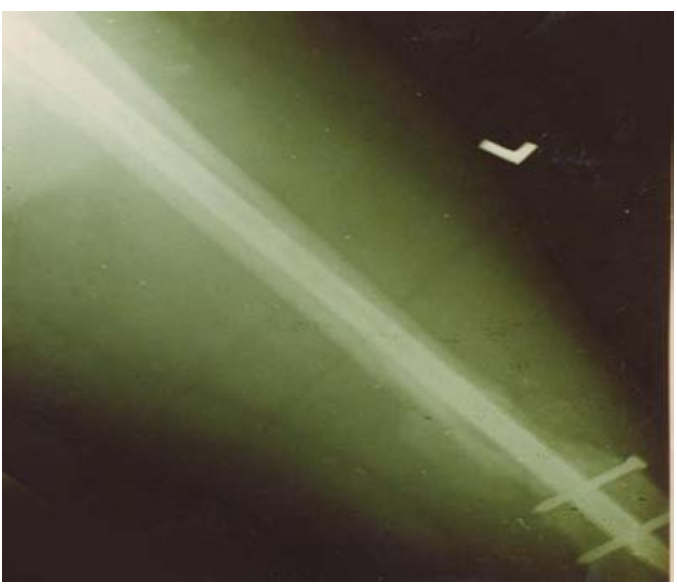

$\mathrm{X}$-ray showing 18 weeks post operative antero posterior view

was 12 to 32 weeks in the other groups.(table 8) 
Table 8: Studies showing fracture healing (interlocking intramedullary nailing)

\begin{tabular}{lc}
\hline Studies & Time of healing \\
\hline Johnson et al(1984) & 13.8 weeks \\
Kempf et al (1985) $^{\mathbf{1 0}}$ & 17 weeks \\
Johnson and Greenberg (1987) $^{\mathbf{1 1}}$ & 14 weeks \\
Christie et al (1988) $^{\mathbf{1 2}}$ & 17 weeks \\
Sojbjerg et al (1990) & 12 weeks \\
Wiss et al (1990) $^{\mathbf{1 3}}$ & 32 weeks \\
Anastopoulos et al (1993) & 18 weeks \\
Hajek et al (1993) & 12 weeks \\
Mahmood et al (1993) & 32 weeks \\
Kropfl et al (1995) & 14 weeks \\
Baixuli et al (1998) & 20 weeks \\
Present study & 17.7 weeks
\end{tabular}

\section{Conclusion:}

Interlocked Intramedullary Nailing of comminuted femoral shaft fracture is a gold standard method of treatment with advantages of predictability, low rate of complications and full weight bearing is significantly earlier.

\section{References:}

1. Bucholz RW, Jones A. current concepts review fractures of the shaft of the femur. J Bone joint Surg 1991; 10 (73A):1561-66.

2. Winquist RA, Hansen ST. Comminuted fractures of the femoral shaft treated by intramedullary nailing. Orthop clin North Arm 1980; 11(3):633-48.

3. Winquist RA, Hansen ST Jr, Clawson DK. Closed intramedullary nailing of femoral fractures: A report of five hundred and twenty cases. J Bone joint Surg 1984; 66A: 529-39

4. Gustilo RB, Mendoza RM, Williams DN. Problems in the management of type III(sereve) open fractures: A new classification of type III open fractures. J Trauma 1984; 24: 742-46.

5. Rockwood CA Jr, Green DP, Bucholz RW, Heckman JD(eds).Rockwood and Green's Fractures in Adults. $4^{\text {th }}$ Ed. Philadelphia: Lippincott Raven publishers, 1996; 2:1827-1918.

6. Russell TA, Taylor JC, Lavelle DG, Beals NB, Brumfied Dc, Durham AG. Mechanical 
characterization of femoral interlocking intramedullary nailing interlocked nailing for treatment of segmental fractures of the femur. J Bone joint Surg 1990; 72A (5):724-28-40

7. Russell TA. Biomechanical concepts of femoral intramedullary nailing (Review paper), Intern J orthop Trauma 1991; 1(1): 36-51.3.4.

8. Thoreson Bo, Alho A, Ekeland $A$ et al .Interlocking intramedullary nailing in femoral shaft fracture. A report of forty-eight cases. J Bone joint Surg 1985; 67A:1313-20.

9. Johnson KD, Johnston DWC, Parker B. comminuted femoral shaft fractures/ treatment by roller traction, cerclage wires and intramedullary nail or an interlocking nail. J bone joint Surg 1984; 66A:12-22.

10. Kempf, Grosse A, Beck G. Closed locked intramedullary nailing. Its application to comminuted fractures of the femur.J bone joint Surg 1985; 67A (5); 709-20.

11. Johnson KD, Greenberg M. Comminuted femoral shaft fractures. Orthop clin North Am 1987; 18(1): 133-47.

12. Christie J, Court- brown C, Kinninmonth AWG, Howie CR. Intramedullary locking nails in the management of femoral shaft fractures, $\mathrm{J}$ Bone joint Surg (Br)1988;70B 206-10.

13. Sojbjerg J, EiskjaerS. Larsen FM. Locked Nailing of comminuted and unstable fractures of the femur. J Bone joint Surg 1990; 72 B (1): 2325.

14. Anastopoulos G,Asimakopoulos A,Exarchou E Pantazopoulous $\mathrm{T}$, closed interlocked nailing in comminuted and segmentel femoral shaft fractures J. trauma 1993;35(5):772-75

15. Hajek PD, Bicknell HR, Bronson WE, Albright JA, SahaS, Louisiana S. The use of one compared with two distal screws in the treatment of femoral shaft fractures with interlocking intramedullary nailing: A clinical and biomechanical analysis. J bone joint Surg 1993; 75A (4):519-25.

16. Mahmood R,Shah AA, Shah GA, Chatha M, Sultan S. Closed intramedullary nailing of femoral shaft fractures. J Pak Orthop Assoc 1993;2(7):16-18

17. Mahmood R,Shah AA, Shah GA, Chatha M, Sultan S. Closed intramedullary nailing of femoral shaft fractures. J Pak Orthop Assoc 1993;2(7):16-18

18. Kropfl A, Naglik H, Primaveri C Hertz H. Unreamed intramedullary nailing of femoral fractures.J Trauma 1995; 38(5):717-26.

19. Baixauli F Sr, Baixauli EJ, Sanhez Alepuz E, Baixauli F Jr. Interlocked intramedullary nailing for treatment of open femoral shaft fractures. Clin orthop Related Res 1998;350:67-73

Correspondence Address: Dr. Abul Kalam Mohammad, Department of Orthopedics, Nobel Medical College and Teaching Hospital, Kanchanbari-5, Bitatnagar. 